\title{
Utilization of Electrical Measuring Instruments at Technical College Level
}

\author{
Sani, Mustapha Sumaila
}

\begin{abstract}
The study was an attempt to determine factors affecting the effective utilization of electrical measuring instruments at Technical College level in Kano state, Nigeria. The study was guided by three research questions. Electrical trade teachers from Technical Colleges in Kano state responded to a 35 item structured questionnaire. Simple means and standard deviation were used for the data analysis. The result indicates that respondents have difficulty in teaching measurement of angular speed, use of oscilloscope and determination of electrical waveforms or they might never tough the tasks. It also reveals that the effective utilization of electrical instruments is affected by lack of relevant instructional materials, lack of power supply and lack of relevant instructional manuals. The study therefore recommends the use computer simulations in teaching the difficult tasks, as well as the provision of computers and simple audio visual devices in the laboratories.
\end{abstract}

Keywords: Utilization, Electrical Measuring Instruments and Technical College.

\section{Introduction}

The guiding principle of education in Nigeria according to UNESCO (2010) is the equipping of every citizen with such knowledge, skill, attitude and values as to enable him/her to derive maximum benefits from his/her membership in society, lead a fulfilling life and contribute to the development and welfare of the community. The broad goals of education in Nigeria are therefore the inculcation of national consciousness and national unity; inculcation of correct types of values and attitudes for the survival of the individual and the Nigerian society; and training for understanding the world around (FRN, 2004). Accordingly, one of the strategic objectives of Nigeria Vision 20:2020 is to improve the nation's prospects for achieving the Millennium Development Goals (MDG) and creating employment in a sustainable manner. In order to achieve the long-term broad objectives of the Millennium Development Goals and the National Economic Empowerment and Development Strategies (NEEDS), one of the challenges is for the nation to raise the quality and standard of education to international comparative levels.

These broad goals are far from being achieved when one considers the wide gap that existed due to dilapidated infrastructures and inadequacy of skilled personnel and equipment. The United Nations Educational, Scientific and Cultural Organization (UNESCO, 2013 in Idoko, 2013) has indicated that Nigeria has one of the worst global practices in education. This is coupled with the issue of incessant power failure with makes workshop activities in schools and Colleges nearly impossible.

The use of electrical measuring instruments is an important workshop/laboratory activity in all electrical and electronic related trade subjects in the National Board for Technical Education (NBTE) curriculum. It is an activity that requires skill and relevant instrument in order for the students to perform. Therefore all schools/colleges that offer such trade subjects must make adequate provisions for effective instruction on the proper utilization of the instruments used for this purpose.

This study involved the use of descriptive survey to conduct a needs assessment in order to ascertain the current situation as it relates to the use of basic electrical measuring instruments in laboratory practices in Technical schools in Kano state. The survey covers all the Secondary schools and Technical Colleges in Kano state that offer trade subjects that require the use of electrical measuring instruments. The trade areas are those covered by the West Africa Examination Council (WAEC) and the National Business and Technical Examination Board (NABTEB) syllabus. Sampled Basic Technology teachers will be required to complete

The study was conducted in Kano state, north-western Nigeria. All the NBTE accredited Technical Colleges and Secondary schools that offer the National Certificate Examination (NTC) and Senior Secondary Certificate Examination (SSCE) formed the study area. The population of the study comprises of all fifty (50) electrical/electronic trade teachers in Technical Colleges and some Secondary Schools in Kano state. For the fact that whole population is small and assessable, the study uses all of them as the sample.

The instrument for data collection was a 35 items structured questionnaires which, in addition to demographic data, provided answers relating to current laboratory practices in the use of electrical measuring instruments in the schools/colleges. The questionnaire was validated by experts in technical and vocational education from the Abubakar Tafawa Balewa University, Bauchi and the University of Nigeria. The instruments were administered personally by the researcher, and were retrieved after completion. A total of fifty (50) 
questionnaires were distributed out of which forty two (42), representing eighty four percent (84\%) were completed and retrieved.

\section{Statement of the Problem}

An important aspect of designing, maintaining and servicing electrical/electronic equipment and circuits is in testing and measurement. In order to find the values of electrical quantities such as current, voltage, and resistance, it is necessary to transform or change these quantities into a measurable quantity or value. This can only be achieved through the use of an instrument that can indicate the magnitude of quantities either by position of a pointer moving over calibrated scale (analogue) or in the form of decimal number (digital). These type of instruments are called electrical measuring instruments; and they are instruments used in various electrical/electronic school laboratories for the conduct of practical instruction and examinations in Basic Electricity, Applied Electronic, Electrical Installation work, Refrigeration and Air-conditioning and all other areas of the electrical trade in the National Board for Technical Education (NBTE) curriculum (W.A.E.C. 2012 and NABTEB, 2011).

The questions raised by this study were, are the instruments adequately provided in our various school workshops? Are they adequate and in a functional condition? Are the simple laboratory operations involving utilization of these instruments easily conducted? It was in order to provide answers to these and other related questions that this study was conducted.

\section{Purpose of the Study}

The main purpose of this work was to investigate the factors affecting the effective utilization of electrical measuring instruments in some post primary technical institutions in Kano state. The study will therefore Endeavour to:

1. Identify difficult tasks/concepts in the use of electrical measuring instruments.

2. Determine the factors responsible for the difficulty of the tasks/concepts.

3. Determine the availability/unavailability of some basic measuring instruments in the schools/colleges.

\section{Research Questions}

The study was guided by the following research questions:

1. What are the basic tasks/concepts involved in the use of electrical measuring instruments in the laboratories?

2. How difficult/easy are these tasks/concepts in using electrical measuring instruments?

3. What are the factors responsible for the difficulty of the tasks/concepts?

\section{Significance of the Study}

The work is expected to provide baseline data on the current laboratory/workshop practices on the use of electrical measuring instruments at post basic education level. The data will be of imminent use to the state government in outlining areas of inadequacies and evaluation of the current practices with a view to devising new approaches to the teaching of the use of these instruments.

\section{Research Question 1}

\section{Results}

What are the basic tasks/concepts involved in the use of electrical measuring instruments in the laboratories?

\begin{tabular}{llcc}
\hline \multicolumn{1}{c}{ Tasks } & N & Mean & Std. Deviation \\
\hline Item6: Measurement of current passing through a conductor & 42 & 2.86 & .472 \\
item7: Measurement of voltage across a conductor & 42 & 2.95 & .216 \\
item8: Measurement of resistance of a conductor & 42 & 2.81 & .505 \\
item9: Measurement of frequency & 42.36 & 1.24 & .791 \\
item10: Measurement of angular speed & 42 & .81 & .617 \\
item11: Use of ammeter & 42 & .594 \\
item12: Use of voltmeter & 42 & 2.86 \\
item13: Use of frequency meter & 42 & 2.50 & .472 \\
item14: Use of tachometer & 42 & .672 \\
item15: Use of multimeter (Analogue) & 42 & 2.52 & .786 \\
item16: Use of multimeter (Digital) & 42 & 2.36 & .804 \\
item17: Use of transistor tester & 42 & 2.26 & .791 \\
item18: Use of megger tester & 42 & 2.29 & .767
\end{tabular}




\section{TABLE 1: Descriptive analysis of Difficulty Levels of Some Basic Tasks in the Use of Electrical}

\section{Measuring Instruments}

Table 1 presents an analysis of some basic tasks involved in the use of electrical measuring instruments. Some 13 items were identified.

\section{Research Question 2}

How difficult/easy are these tasks/concepts in using electrical measuring instruments?

From table 1, the levels of difficulty of each item were calculated using t-test. A difficulty level of 2.0 above is set as the cutoff point. As can be observed, all the items have a difficulty level above this point except items 10, 19 and 20. This shows that the teachers either find the task of teaching of these items difficult, or they have never tough the concepts/tasks.

\section{Research Question 3}

What are the factors responsible for the difficulty of the tasks/concepts?

\begin{tabular}{lccc}
\hline \multicolumn{1}{c}{ Factors } & $\mathrm{N}$ & Mean & Std. Deviation \\
\hline Item21: Lack of power supply & 40 & 1.58 & .984 \\
item22: Lack of relevant operation manuals & 42 & 1.67 & 1.052 \\
item23: Abstract nature of the tasks/concepts & 40 & 2.33 & 1.118 \\
item24: Obsolete instruments & 42 & 2.86 & 1.389 \\
item25: Inadequate instruments & 42 & 2.14 & 1.026 \\
iten26: Learner's inabilities & 42 & 2.60 & 1.083 \\
item27: Communication problem (language) & 42 & 2.29 & 1.330 \\
item28: Inadequate time allocation & 42 & 2.38 & 1.513 \\
item29: Lack of relevant instructional materials & 42 & 1.76 & .821 \\
item30: Poor laboratory situation & 42 & 2.02 & 1.199 \\
item31: Teachers unpreparedness & 42 & 3.38 & 1.248 \\
item32: Inadequate reference materials (textbooks) & 42 & 2.05 & 1.229 \\
item33: Student's Lack of interest & 42 & 2.40 & 1.251 \\
item34: Teacher's Lack of interest & 42 & 2.79 & 1.371 \\
item35: Teacher's lack of practical/manipulative skills & 42 & 2.55 & 1.273 \\
Valid N (listwise) & 40 & &
\end{tabular}

TABLE 2: Descriptive analysis of Factors Responsible for the Difficulty in the Use of Electrical

\section{Measuring Instruments}

Table 2 presents a t-test analysis of the factors responsible for some of the difficulties in the use of electrical measuring instruments. A 5-point Likert type rating scale was used to collect the data, and a cutoff point of 3 was set. From table 2, therefore, all the items fall below the cutoff point except item 31. Equally, items 21,22 and 29 score the lowest.

\section{Findings}

From the analysis in tables 1 and 2, the following findings emerged:

1. Respondents find difficulty in teaching measurement of angular speed, use of oscilloscope and determination of electrical waveforms or they might never tough the tasks.

2. The following factors may be responsible for the difficulty in the teaching of the use of electrical measuring instruments:

i. Lack of relevant instructional materials.

ii. Lack of power supply.

iii. Lack of relevant instructional manuals.

\section{Discussion of the Findings}

From the findings of the study, it is evident that there is a dearth of relevant instruction materials, problem of inadequate power supply as well as the inadequacy of proper instructional manual on how to use the instruments. This agrees with the assertions of UNESCO (2010) that Nigeria is recording the worst global education indicators. also in line with the Kano State Education Strategic Plan (KSG, 2008), a Technical 
College/ Vocational Training Center was establish in each of the forty four (44) Local Government Areas of the state. This development also creates additional problem by the deployment of some the resources of the existing Technical Colleges to the new ones. It also agrees with the findings of Medugu and Mustapha (2013) that the use of improvised electrical models can greatly enhance the learning of Electrical trade subjects at Technical College level.

\section{Conclusion}

The effective utilization of electrical measuring instrument for instruction in Technical Colleges is faced with the problems associated with difficulty of some tasks on one hand; and that of inadequacy of power supply, instructional materials and operation manuals on the other hand. This can be observed from the findings of this research.

\section{Recommendations}

The paper wish to recommend that:

1. Technical Colleges should introduce the use computer simulations in teaching the difficult tasks.

2. Computers and simple audio visual devices be provided in college Basic Electricity laboratories.

\section{References}

[1]. Federal Government of Nigeria (2004), National Policy on Education, $\left(4^{\text {th }}\right.$ ed) Lagos: NERDC Publishers

[2]. Idoko, C. (2013). Nigeria has worst global education indicators - UNESCO, daily Trust online, assessed on Thursday $14^{\text {th }}$ march, 2013

[3]. Kano State Government (2008). Kano State Revised Education Strategic Plan, 2009-2018 (pp 25). PDF document retrieved on $14 / 01 / 2013$

[4]. Medugu. J.D. and Mustapha, B.G.A. (2013). Comparison of the Effects of Improvised Electrical Models On Students Academic Achievement In Male And Female Technical Colleges In Borno State, Nigeria, Journal of Education and Practice, Vol.4, No.6, 2013 (pp55-59) www.iiste.org

[5]. National Business and Technical Examinations Board (2011). National Technical Examinations Curriculum (Engineering Trades). Assessed from http://nabtebeworld.com on $3^{\text {rd }}$ September, 2013.

[6]. West African Examination Council (2012). WAEC Syllabus, from http://registration.waecdirect.org/syllabus.html, assessed on $3^{\text {rd }}$ September, 2013.

[7]. United Nations Educational, Scientific and Cultural Organization (2010). World Data on Education. $7^{\text {th }}$ edition 2010/2011, http://www.ibe.unesco.org. assessed on 01/05/2013 